\title{
Pyrolytic 3D Carbon Microelectrodes for Electrochemistry
}

Hemanth, Suhith; Caviglia, Claudia; Amato, Letizia; Anhøj, Thomas Aarøe; Heiskanen, Arto; Emnéus, Jenny; Keller, Stephan Sylvest

\author{
Published in: \\ ECS Transactions \\ Link to article, DOI: \\ 10.1149/07201.0117ecst \\ Publication date: \\ 2016 \\ Document Version \\ Peer reviewed version \\ Link back to DTU Orbit
}

Citation (APA):

Hemanth, S., Caviglia, C., Amato, L., Anhøj, T. A., Heiskanen, A., Emnéus, J., \& Keller, S. S. (2016). Pyrolytic 3D Carbon Microelectrodes for Electrochemistry. ECS Transactions, 72(1), 117-124.

https://doi.org/10.1149/07201.0117ecst

\section{General rights}

Copyright and moral rights for the publications made accessible in the public portal are retained by the authors and/or other copyright owners and it is a condition of accessing publications that users recognise and abide by the legal requirements associated with these rights.

- Users may download and print one copy of any publication from the public portal for the purpose of private study or research.

- You may not further distribute the material or use it for any profit-making activity or commercial gain

- You may freely distribute the URL identifying the publication in the public portal 
See discussions, stats, and author profiles for this publication at: https://www.researchgate.net/publication/303397805

\section{Pyrolytic 3D Carbon Microelectrodes for Electrochemistry}

Article in ECS Transactions · May 2016

DOI: 10.1149/07201.0117ecst

CITATION

7 authors, including:

Suhith Hemanth

Technical University of Denmark

8 PUBLICATIONS $\mathbf{1 4}$ CITATIONS

SEE PROFILE

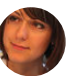

Letizia Amato

Technical University of Denmark

13 PUBLICATIONS 132 CITATIONS

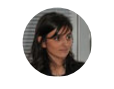

Claudia Caviglia

Technical University of Denmark

14 PUBLICATIONS 104 CITATIONS

SEE PROFILE

SEE PROFILE

Arto Heiskanen

Technical University of Denmark

63 PUBLICATIONS 782 CITATIONS

SEE PROFILE

Some of the authors of this publication are also working on these related projects:

3D Nanocarbon chips for microsupercapacitors and ultrasensitive detection View project

IDUN drug View project 


\section{Pyrolytic 3D Carbon Microelectrodes for Electrochemistry}

S.Hemanth ${ }^{\mathrm{a}}$, C.Caviglia ${ }^{\mathrm{a}}$, L. Amato ${ }^{\mathrm{a}}$, T.A. Anh $ø \mathrm{j}^{\mathrm{b}}$, A.Heiskanen ${ }^{\mathrm{a}}$, J. Emnéus ${ }^{\mathrm{a}}$, and

S.S. Keller ${ }^{\mathrm{a}}$

aDepartment of Micro- and Nanotechnology, DTU Nanotech, DK- 2800

${ }^{\mathrm{b}}$ DTU Danchip, 2800 Kongens Lyngby, Denmark

This work presents the fabrication and characterization of suspended three-dimensional (3D) pyrolytic carbon microelectrodes for electrochemical applications. For this purpose, an optimized process with multiple steps of UV photolithography with the negative tone photoresist SU-8 followed by pyrolysis at $900^{\circ} \mathrm{C}$ for $1 \mathrm{~h}$ was developed. With this process, microelectrode chips with a three electrode configuration were fabricated and characterized with cyclic voltammetry $(\mathrm{CV})$ using a $10 \mathrm{mM}$ potassium ferri-ferrocyanide redox probe in a custom made batch system with magnetic clamping. The 3D pyrolytic carbon microelectrodes displayed twice the higher peak current compared to $2 \mathrm{D}$.

\section{Introduction}

Carbon materials have several attractive characteristics for microelectrodes in electrochemical applications, such as a wide potential window, good electrochemical activity, chemical stability, and ease in surface functionalization (1). The most common carbon microfabrication techniques (i.e. screen printing) produce two-dimensional (2D) electrodes. However, 3D microelectrodes provide larger surface area and thereby could enhance the sensitivity in electrochemical detection (2). Hence, several 3D microfabrication techniques have been explored amongst which the carbon MEMS (CMEMS) approach is the most promising one for the fabrication of conductive 3D microstructures. In C-MEMS, a patterned polymer template is treated at high temperature $\left(\sim 900^{\circ} \mathrm{C}\right)$ in inert atmosphere $\left(\mathrm{N}_{2}\right.$ or $\left.\mathrm{Ar}\right)$ and transformed into pyrolytic carbon. This process enables fabrication of $2 \mathrm{D}$ and $3 \mathrm{D}$ electrodes with the possibility to tailor designs and thereby sensitivities for electrochemical sensing applications. Due to this, pyrolytic carbon microelectrodes are becoming increasingly attractive for numerous applications, such as in novel sensors and scaffolds for cell monitoring (3-5). Nevertheless, fabrication of electrically conductive 3D carbon microelectrodes (3DCMEs) with structural dimensions that are comparable to the size of biological cells still remains challenging.

One of the most important factors in 3D C-MEMS technology is the definition of a mechanically stable 3D polymer precursor template for pyrolysis. Recently, various 3D polymer fabrication technologies evolved. Microfabrication methods such as two-photon, e-beam and X-ray lithography proved to be powerful tools in developing 3D micro/nanostructures but unfortunately still display a very low throughput and the required equipment is rather expensive $(6,7)$. Some of the additive manufacturing technologies such as 3D printing or stereolithography provide a higher throughput but lack the micron range resolution (8). Therefore, in most C-MEMS processes, polymer microstructures were fabricated using standard UV photolithography with the chemically enhanced, negative tone epoxy photoresist SU-8 (9-11). This method is readily available 
at a reasonable cost. Typically, SU-8 photolithography comprises spin coating, solvent evaporation, UV-exposure, polymerization and development $(12,13)$. Each of these steps affect the photolithographic resolution and the properties of SU-8 structures such as stress or adhesion to the substrate. Therefore, depending on the desired application different process parameters have to be optimized to obtain well-resolved and mechanically stable 3D microstructures (14).

Different fabrication processes have been proposed to obtain suspended SU-8 microstructures. The most common process involves adding a polymerization-stop-layer between the structures to be suspended and the substrate (15). The complexity of this fabrication process increases as the structures become multilayered (i.e. more 3D). Another method includes doping of the SU-8 photoresist with nanoparticles to control the thickness of freestanding 3D structures (11). However, such an addition of $\mathrm{Fe}_{2} \mathrm{O}_{3}$ nanoparticles requires a number of preparation steps which severely limit the flexibility of the process. The most promising processes to define suspended layer so far are using a partial UV exposure of SU-8 photoresist films either at a lower wavelength $(313 \mathrm{~nm})$ or/and a very low dose $(15,16)$.

In this work, we developed a multi-step UV photolithography process to fabricate a 3D SU-8 polymer template which was pyrolyzed to define 3D carbon microelectrodes for electrochemistry. The fabrication of suspended microstructures in a single layer of SU-8 was optimized. The process was used to define 3D carbon microstructures acting as the working electrodes (WE) in microelectrode chips with a three electrode configuration. The electrochemical performance of 2D and 3D carbon microelectrodes was compared with cyclic voltammetry $(\mathrm{CV})$ in a batch system with $10 \mathrm{mM}$ potassium ferri-ferrocyanide standard redox probe.

\section{Methods}

\section{$\underline{\text { Microelectrode chips }}$}

The microelectrode chips were fabricated with multiple steps of UV photolithography followed by pyrolysis as shown schematically in Figure 1.a - e. First, the process of fabricating suspended layers from a single layer of SU-8 was optimized by adjusting the partial exposure dose $\left(\mathrm{D}_{3}\right)(16)$. The optimized process was used to fabricate 3DCMEs on the working electrode of the microelectrode chips. Figure 1.f and g shows the top view of the microelectrode chip without and with passivation layer (SU-8). The process is explained along the cross-section AA`(Figure 1. f).

Approximately $5 \mathrm{ml}$ of negative photoresist (SU-8 2005 from MicroChem, USA) were manually dispensed on a 4-inch $\mathrm{Si} / \mathrm{SiO}_{2}$ substrate and spin coated (RCD8 T, Süss MicroTec, Germany) to deposit a $6 \mu \mathrm{m}$ thick layer. A solvent evaporation for $2 \mathrm{~h}$ at room temperature was followed by a UV exposure step with an exposure dose, $\mathrm{D}_{1}=147 \mathrm{mJcm}^{-2}$ in an EVG620 aligner (EVGroup, Austria) to define the working and counter electrodes (Figure 1.a) (13). The aligner was equipped with a mercury lamp and a long pass filter (SU-8 filter), adjusted to a constant intensity of $7 \mathrm{mWcm}^{-2}$ at $365 \mathrm{~nm}$. This is followed by a post-exposure bake (PEB) at $50{ }^{\circ} \mathrm{C}$ for $1 \mathrm{~h}$ on a programmable hotplate (Harry Gestigkeit GmbH, Germany). A second layer of SU-8 2075 was manually dispensed and 
spin coated to a thickness of $66 \mu \mathrm{m}$. The edge bead was removed by dispensing propylene glycol methyl ether acetate (PGMEA) at the edge of the rotating wafer (300 rpm). A soft bake (SB) at $50{ }^{\circ} \mathrm{C}$ for $6 \mathrm{~h}$ is followed by a two-step UV photolithography to achieve 3D microstructures. The first exposure $\left(\mathrm{D}_{2}=147 \mathrm{mJcm}^{-2}\right)$ defines the supporting pillars (Figure 1.b) and the partial exposure $\left(\mathrm{D}_{3}\right)$ defines the suspended layer (Figure 1.c). $\mathrm{D}_{3}$ was optimized to limit the crosslinking to the top of the SU-8 layer. This was followed by a PEB at $50{ }^{\circ} \mathrm{C}$ for $8 \mathrm{~h}$. Development was performed in PGMEA in two steps of $10 \mathrm{~min}$ followed by isopropanol rinse for $30 \mathrm{~s}$ and drying in air (Figure 1.d). Next, an additional flood exposure with a total dose $\mathrm{D}=500 \mathrm{mJcm}^{-2}$ and a hard-bake at $90{ }^{\circ} \mathrm{C}$ for $15 \mathrm{~h}$ were performed to increase the structural stability of SU-8 achieved by improved crosslinking. The polymer template is pyrolyzed in an ATV PEO604 furnace (ATV Tech., Germany) in inert atmosphere $\left(\mathrm{N}_{2}\right)$ in two steps, $200{ }^{\circ} \mathrm{C}$ for $30 \mathrm{~min}$ and $900{ }^{\circ} \mathrm{C}$ for $1 \mathrm{~h}$ with a ramp of $2^{\circ} \mathrm{min}^{-1}$ to produce suspended carbon microstructures.

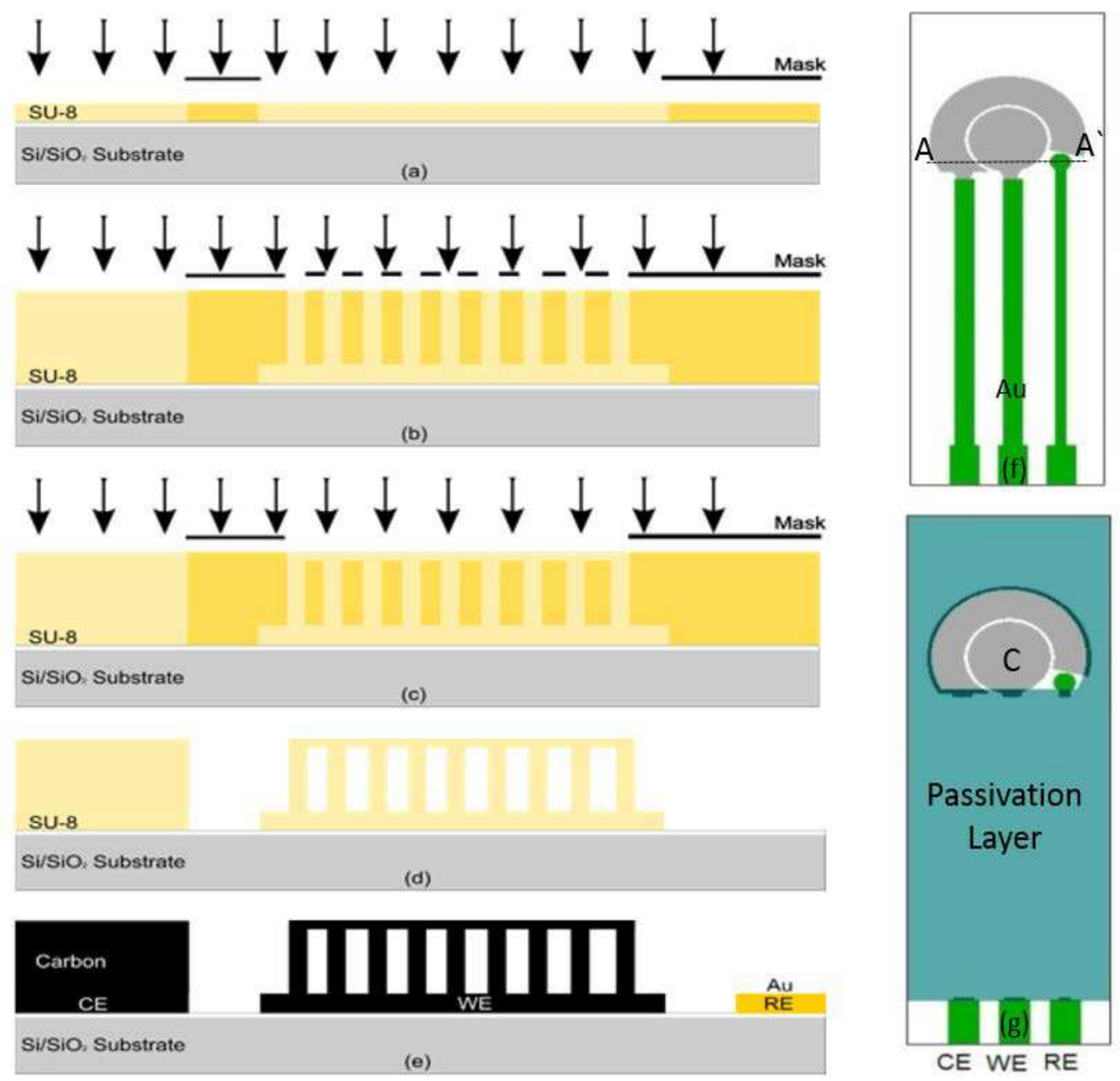

Figure 1. Schematic of the microfabrication process (a) SU-8 (2005) is spin coated, baked UV exposed and post exposure baked (b) Second layer of SU-8 (2075) is spin coated, baked and UV exposed (c) short UV exposure and post exposure bake (d) Development in PGMEA (e) Pyrolysis at $900^{\circ} \mathrm{C}$ for $1 \mathrm{~h}$ and e-beam Au deposition through a shadow mask (f) and (g) shows the top view of the microelectrode chip without and with passivation (SU-8) layer 
A gold pseudo-reference electrode and gold contact pads were deposited by e-beam evaporation through a shadow mask (Figure 1.e). For passivating the contact leads, a $2 \mu \mathrm{m}$ thick film of SU-8 2002 was spin coated and patterned as described above for the SU-8 2005 including the final flood exposure and hard bake.

\section{Batch system with magnetic clamping}

A self-aligning, magnetic clamping system was developed for electrochemical characterization of the microelectrode chips. Figure 2 shows the schematic of different layers in the batch system. Rare earth magnets were used to facilitate clamping and exchange of the microelectrode chips. $\mathrm{A} \mathrm{CO}_{2}$ laser (Epilog Laser, USA) was used for drilling and dicing of the PMMA parts followed by bonding them using pressure sensitive adhesive (PSA) in a bonding press (P/O Webber, Germany) at $35^{\circ} \mathrm{C}$ with a pressure of 150 bar for $10 \mathrm{~min}$. The top plate defines a circular well with diameter $8 \mathrm{~mm}$ above the electrode area suitable for experiments in batch conditions. Furthermore, a trench was engraved in the top plate accomodating an O-ring to avoid any leakage in the cavity. The bottom plate provided the slot for placing the microelectrode chips.

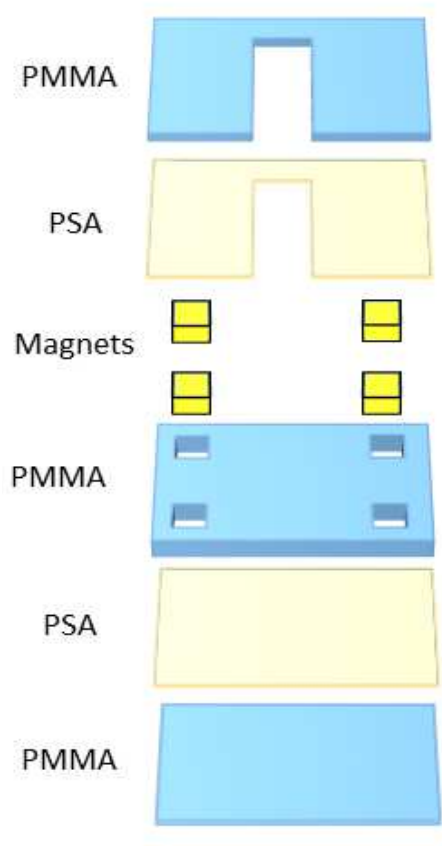

Bottom plate

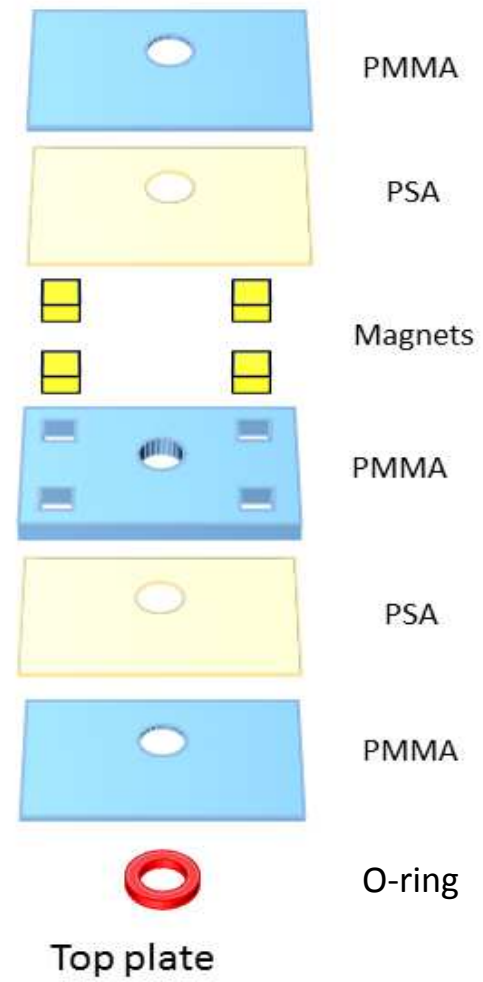

Figure 2. Different components in the magnetically clamped batch system

\section{Electrochemical Characterisation}

For electrochemical analysis, cyclic voltammetry (CV) was performed using a standard $10 \mathrm{mM}$ potassium ferri-ferrocyanide redox probe in the batch systems. The microelectrode chips (2D and 3D) were pretreated in $\mathrm{O}_{2}$ plasma (Electronic Diener, Germany) at $50 \mathrm{~W}$ for 60 seconds. Then the chips were placed in the bottom plate of the batch system and sealing was achieved with the O-ring of the top plate. $350 \mu \mathrm{L}$ of redox 
probe were pipetted on the electrode for each measurements. For $\mathrm{CV}$, a voltage of $-0.6 \mathrm{~V}$ to $+0.6 \mathrm{~V}$ in steps of $100 \mathrm{mV}$ was applied with a Potentiostat (Autolab PGSTAT302N, Netherland).

\section{Results and Discussion}

\section{Microfabrication of electrodes}

The optimization of the partial exposure dose $\left(D_{3}\right)$ is critical for the fabrication of 3D suspended SU-8 microstructures. Therefore, an initial series of experiments on various test structures was performed using a single layer of SU-8 and two UV exposures ( $\mathrm{D}_{2}$ and $\mathrm{D}_{3}$ ). Very low exposure doses $\mathrm{D}_{3}$ were selected, in the attempt to achieve a gradient in the concentration of activated photoinitiator molecules in the SU-8 film. The exposure dose $\mathrm{D}_{3}$ was varied from $21-42 \mathrm{mJcm}^{-2}$. The results of the optimization of the partial exposure are shown in Figure 3. The exposure dose, $D_{3}=21 \mathrm{mJcm}^{-2}$ is insufficient for the crosslinking of the top layer of SU-8 film. Hence, after the development in PGMEA only SU-8 pillars from the long UV exposure process remain (Figure 3.a). A higher exposure dose of $\mathrm{D}_{3}=28 \mathrm{mJcm}^{-2}$ limits the crosslinking to the top surface of the SU-8 film, which results in suspended 3D structures (Figure 3.b). The thickness of the suspended layer is $18 \mu \mathrm{m}$. Higher dose $\left(\mathrm{D}_{3}=35 \mathrm{mJcm}^{-2}\right.$ and $\left.42 \mathrm{mJcm}^{-2}\right)$ causes complete crosslinking of the SU-8 film (Figure 3.c, d). These results are in agreement with those obtained by Lim et al. and demonstrate that the process window in terms of exposure dose is very narrow requiring precise control of the exposure conditions (16).

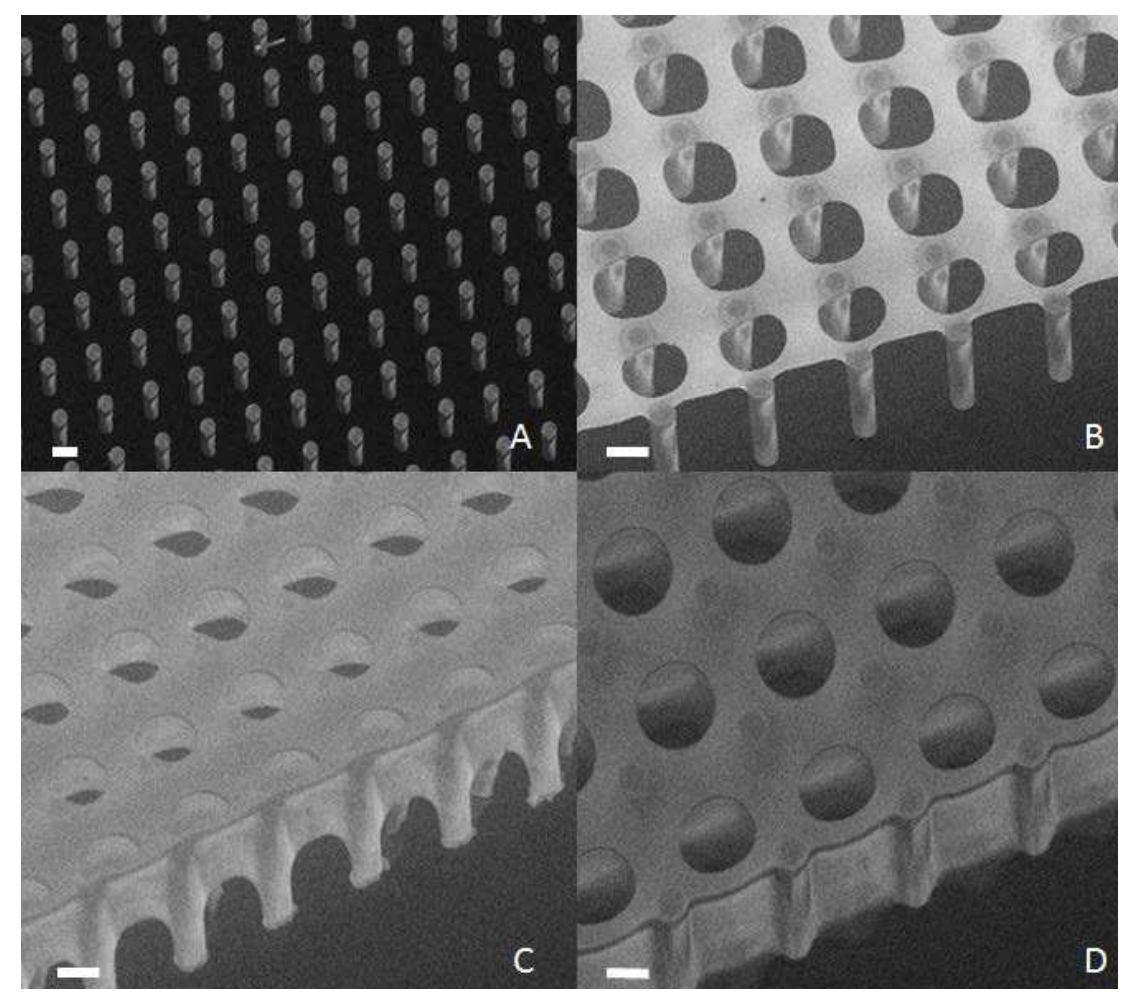

Figure 3. Optimization of partial UV exposure $\left(\mathrm{D}_{2}\right)$ with different exposure dose $\mathrm{D}_{2}$ : (a) $21 \mathrm{mJcm}^{-2}$; (b) $28 \mathrm{mJcm}^{-2}$; (c) $35 \mathrm{mJcm}^{-2}$; (d) $42 \mathrm{mJcm}^{-2}$ (Scale bar - 25 $\mu \mathrm{m}$ ) 
The two steps of UV exposure followed by pyrolysis result in 3D carbon microstructures with various feature sizes (Figure 4). Figure 4 illustrates the carbon microstructures obtained through pyrolysis of the SU-8 template and shows the large shrinkage during pyrolysis. The final height of the structures was $37 \mu \mathrm{m}$ and the thickness of the suspended carbon film was approximately $2.4 \mu \mathrm{m}$. The smallest feature size fabricated in the suspended layer was approximately $5.6 \mu \mathrm{m}$ as shown in Figure 4.d. The results show that once the structures are defined in SU-8, the overall design of the $3 \mathrm{D}$ microstructures are maintained during pyrolysis even though a considerable shrinkage is observed. The optimized process was transferred to the fabrication of the complete microelectrode chip as described in figure 1. Figure 5.a and b shows 2D and 3D working electrodes obtained respectively. And Figure 5 c shows SEM image of working electrode in a 3D microelectrode chip (Figure 5. b).
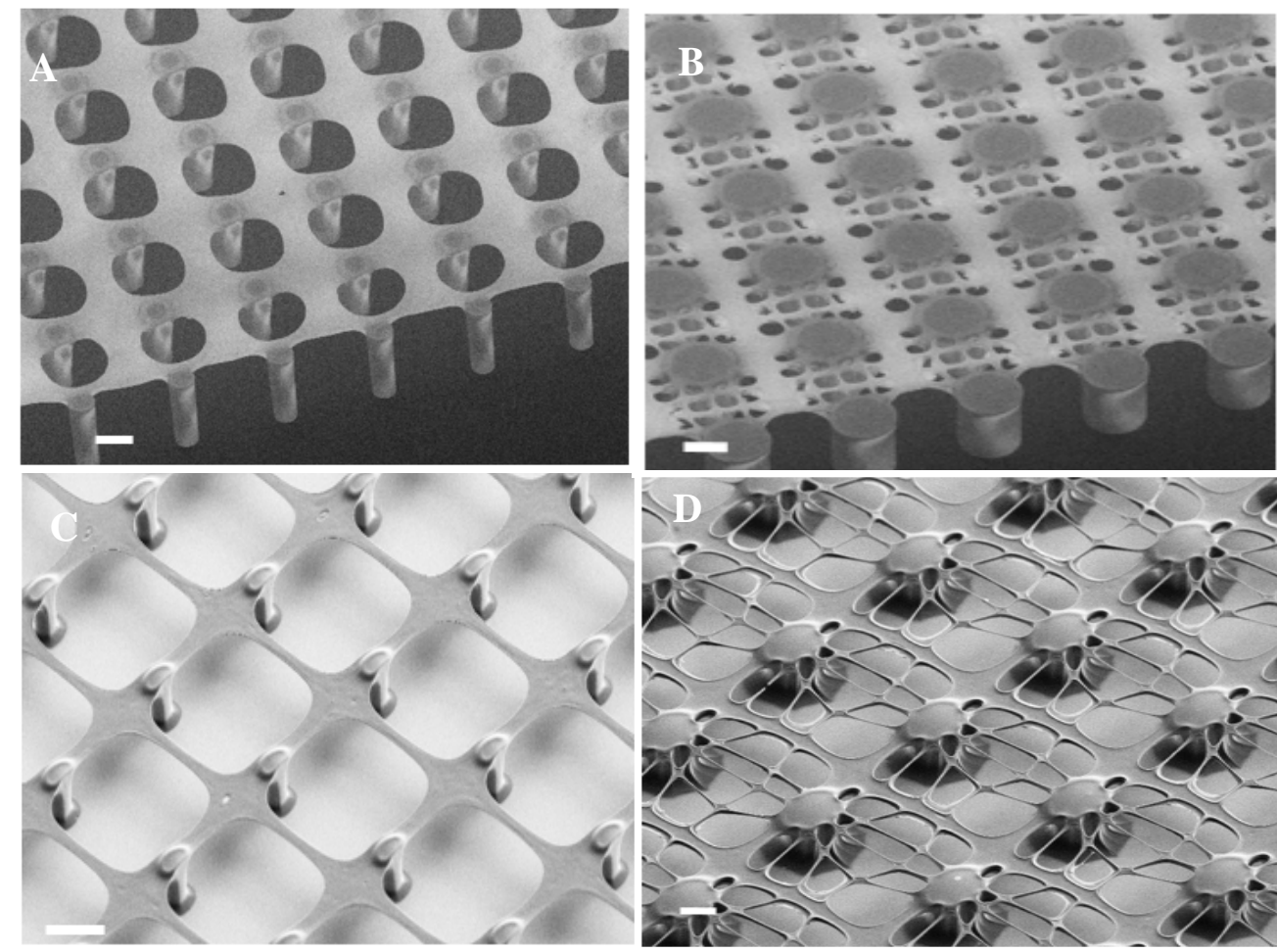

Figure 4. SEM images of (a) and (b) SU-8 polymer template; (c) and (d) are the corresponding carbon microstuctures respectively (Scale bar $-25 \mu \mathrm{m}$ )
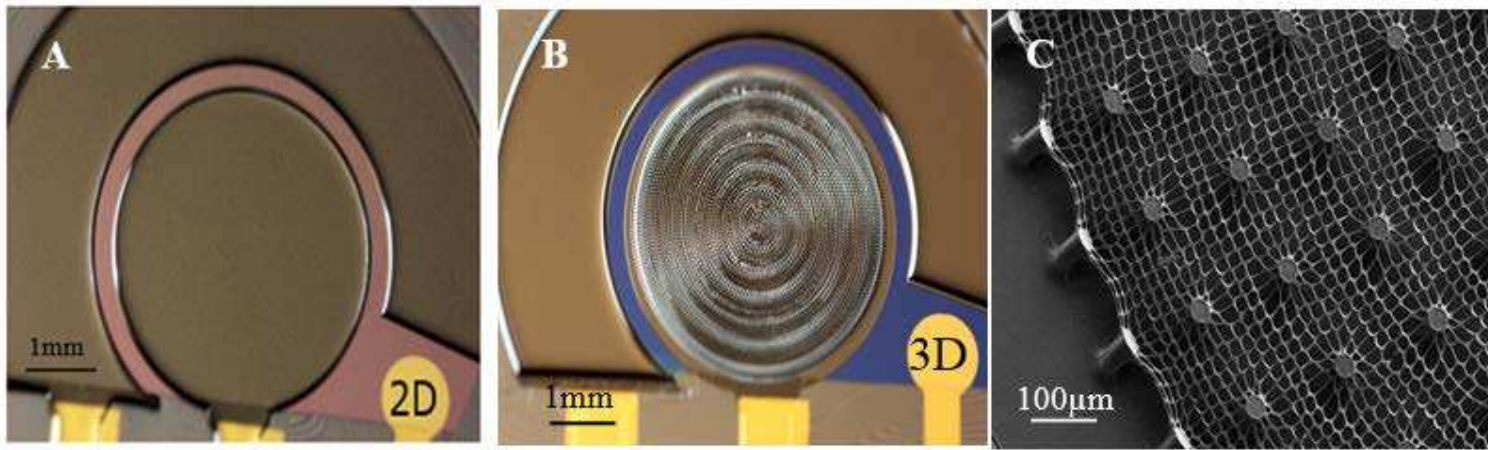

Figure 5. Microelectrode chips (a) 2D working electrode (b) 3D working electrode (c) SEM image of 3D working electrode 


\section{$\underline{\text { Electrochemical characterization }}$}

Figure 5.a and b show the two different microelectrode designs characterized with $\mathrm{CV}$ in the magnetically clamped batch systems. The experimental step-up is shown in Figure 6.a. Figure 6.b shows the mean values and the standard deviation obtained with three microelectrode chips of each design. The peak current $\left(\mathrm{I}_{\mathrm{p}}\right)$ of $2 \mathrm{D}$ and $3 \mathrm{D}$ chips are $29 \mu \mathrm{A}$ and $57 \mu \mathrm{A}$ respectively and the peak separation $\left(\Delta \mathrm{E}_{\mathrm{p}}\right)$ is $0.3 \mathrm{~V}$ and $0.24 \mathrm{~V}$ for $2 \mathrm{D}$ and $3 \mathrm{D}$ chips respectively.
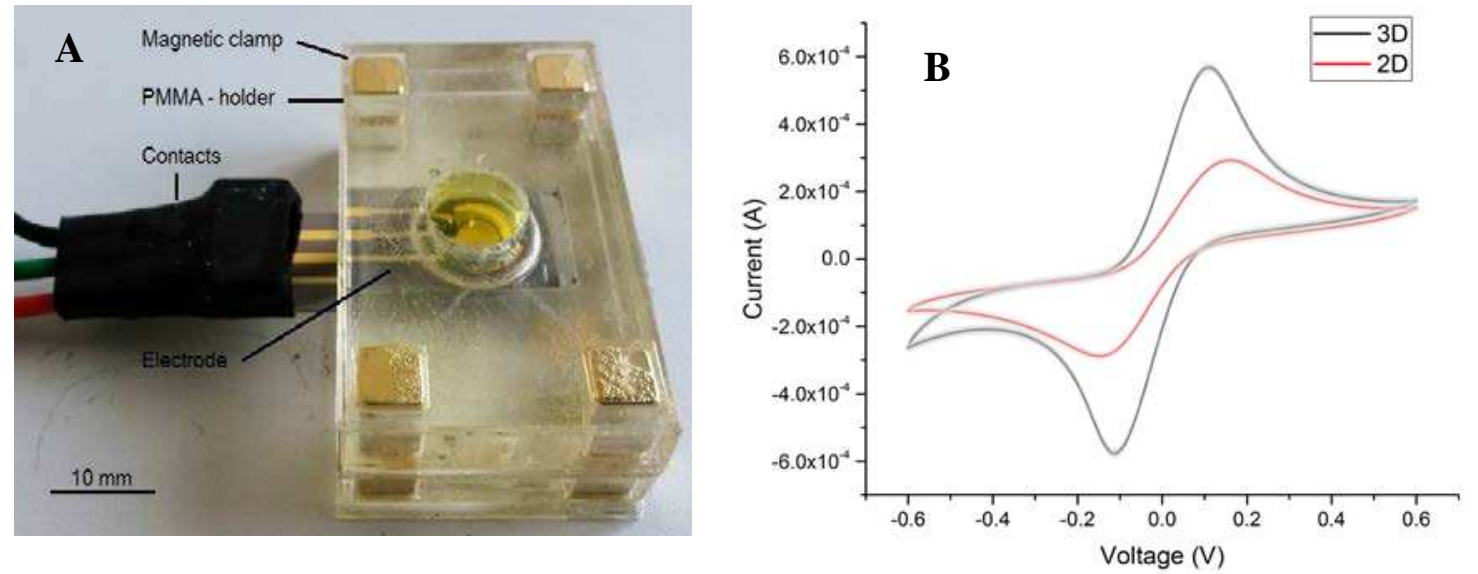

Figure 6. (a) Experimental set-up, (b) CV of 2D and 3D microelectrode chips

The surface area of the working electrode on the 3D microelectrode chips is approximately 3.5 times larger than for the $2 \mathrm{D}$ WE. This explains the higher current when compared to $2 \mathrm{D}$ electrodes.

\section{Conclusion}

SU-8 templates with suspended features in the micrometer range were successfully fabricated and pyrolyzed to obtain microelectrode chips with 3D carbon microelectrodes as working electrode. A two-step $\left(\mathrm{D}_{2}\right.$ and $\left.\mathrm{D}_{3}\right) \mathrm{UV}$ exposure was optimized to fabricate the suspended layer. Small variations of the partial exposure dose $\mathrm{D}_{3}$ result in complete/no crosslinking of the SU-8 layer, demonstrating the narrow window for $\mathrm{D}_{3}$. The higher signal in $\mathrm{CV}$ for 3D microelectrode chips demonstrates an increase of the surface area compared to the 2D configuration which should result in a higher sensitivity for electrochemical sensing. With unique properties of carbon, the proposed fabrication process can be used to customize ad-hoc carbon microelectrodes for specific applications such as biosensors.

\section{Acknowledgments}

The authors acknowledge funding by the Young Investigator Program of the Villum

Foundation, project no. VKR023438. 


\section{References}

1. McCreery RL. Chem Rev.108(7):2646-87 (2008).

2. Kamath RR, Madou MJ. Anal Chem. 86(6):2963-71 (2014).

3. Amato L, Heiskanen A, Caviglia C, Shah F, Zór K, Skolimowski M, et al. Adv Funct Mater. 24(44):7042-52 (2014).

4. Hirabayashi M, Mehta B, Vahidi NW, Khosla A, Kassegne S. J Micromechanics Microengineering.;23(11):115001 (2013).

5. Kassegne S, Wondimu B, Majzoub M, Shin J. Proc SPIE. 7266(619):726615, 1-6 (2008).

6. Campo A del, Greiner C. J Micromechanics Microengineering.17(6):R81-95 (2007).

7. Cadarso VJ, Pfeiffer K, Ostrzinski U, Bureau JB, Racine G a, Voigt A, et al. J Micromechanics Microengineering.21(1):017003 (2011).

8. Melchels FPW, Feijen J, Grijpma DW. Biomaterials.31(24):6121-30 (2010).

9. Martinez-Duarte R. Micromachines.5(3):766-82 (2014).

10. Amato L, Heiskanen A, Hansen R, Gammelgaard L, Rindzevicius T, Tenje M, et al. Carbon.94:792-803 (2015).

11. Wang C, Madou M. Biosens Bioelectron. 20(10 SPEC. ISS.):2181-7 (2005).

12. Shaw JM, Gelorme JD, LaBianca NC, Conley WE, Holmes SJ. IBM J Res Dev. 41(1.2):81-94 (1997).

13. Keller S, Blagoi G, Lillemose M, Haefliger D, Boisen A. J Micromechanics Microengineering. 18:125020 (2008).

14. Amato L, Keller SS, Heiskanen A, Dimaki M, Emnéus J, Boisen A, et al. Microelectron Eng.;98:483-7 (2012).

15. Ceyssens F, Puers R. J Micromechanics Microengineering. 16(6):S19-23 (2006).

16. Lim Y, Heo J-I, Shin H. Sensors Actuators B Chem.192(2014):796-803 (2014). 